\title{
AutOMATION OF THE ACQUISITION AND PROCESSING OF DATA FROM THERMOLUMINESCENCE DOSIMETER READERS
}

\author{
D. C. Rivero-Ramírez', C. García-Trapaga', N. Pavón-Gonzalez', F. Qulles-La Torre², J. Benavides-Benítez². \\ E. Díaz-Bernal ${ }^{3}$ \& D. Molina-Rodríguez ${ }^{3}$
}

\author{
'Institute for Technology and Applied Science Nuclear, InSTEC \\ Ave. Salvador Allende y Luaces, Quinta de los Molinos \\ AP 6163, CP10600 Plaza. Ciudad Habana, Cuba \\ doris@tctn.isctn.edu.cu \\ ${ }^{2}$ Cordoba University \\ Menendes Pidal s/n \\ CP14009, Cordoba, Spain \\ ${ }^{3}$ Center of Protection and Hygiene of the Radiations \\ La Quebrada. San José. Habana. Cuba
}

Received: December 31 ${ }^{\text {st }}$, 2003. Accepted March $3^{d} .2003$

\section{ARSTRACT}

The thermoluminescence dosimeter (TLD) readers used in the Laboratory of External Dosimetry of the Center of Protection and Hyglene from the Radiations are old-fashioned. The data obtained by this equipment must be manually written down in order to subsequently, process them and these data do not remain registered in any memory for future analysis. This paper describes the design and creation of a system that connects these TLD readers to a personal computer. The system includes a data acquisition card with several analogue input channels, counters, timers as well as digital inputs/outputs and software, in order to control the acquisition and processing of the data.

\section{RFSI IMFN}

Los lectores de dosimetros termoluminiscentes (TLD) que se usan en el Laboratorio de Dosimetría Externa del Centro de Protección e Higiene de las Radiaciones son antiguos. Los datos obtenidos con estos equipos deben ser tomados manualmente para ser procesados y no quedan registrados en ninguna otra parte para su futuro análisis. Este trabajo describe el diseño y construcción de un sistema que conecta estos lectores de TLD a una computadora personal. Este sistema incluye una tarjeta de adquisición de datos con varios canales de entradas analógicas, contadores - temporizadores, así como entradas/salidas digitales y además un programa encargado del control de la adquisición v el procesamiento de los datos.

KEYWORDS: Thermoluminescence, Dosimeter, Data Acquisition, Dosimetry, Dose Evaluation.

\section{INTRODUCTION}

Some solld materials have the ability of maintaining the energy absorbed when interacting with ionizing radiation. Later, when these substances are heated to a certain temperature, thev can emit part of that enerøy converted into 
light. This feature is called thermoluminescence (TL). Thermoluminescence as a dosimetric method is one of the most frequently employed in the world today. Thermoluminescence dosimeters (TLD) are applied in environmental dosimetry, radiotherapy, radiodiagnosis and radiological emergencies particularly in personal dosimetry. In our country, this method has been employed in radiodiagnosis, industrial applications, education and metrology for several years.

Three parts or systems constitute the TLD readers. One of them is a heating system, which applies heat to the TL dosimeter. This system must be capable to guarantee an adequate reproducibility of this process. The next part is a light detecting system, which has the function of detecting the pulses of the light emitted by the TL dosimeter during the heating process. The last part is a registration system, which records signals.

The Center of Protection and Hygiene from Radiations (CPHR), in Havana, employs this technique in environmental radiological vigilance and personal dosimetry. For this purpose, they have two TLD readers: a VINTEN 654 and a HARSHAW 2000 B/C. Both TL readers are executing manually all the measurements and data processing.

The thermoluminescence dosimetry offers the possibility of automation of all measurement and information handling processes. This is especially important when personal dosimetry facilities with a large number of users are offered. One can now purchase totally automated readers that include the acquisition programs, analysis and processing of the data. These programs can also be offered separately. However, the employment of these programs is limited to the equipments for which those programs were developed. This situation becomes more complex if they are old fashioned and delivered by different manufactures, as in the case of the CPHR equipment.

On the other hand, one of the important topics to keep in mind in personal dosimetry is the speed of acquiring results of the service. Thus, the speed of processing the information is converted into an important factor within this task. We have approached this by connecting the reader to a personal computer (PC) and by developing a program for data acquisition and processing. Having a program with the already mentioned characteristics would also permit to increase the speed in the processing of the final results. At the same time, this program ensures the quality of the task execution, decreasing the influence of the human factor in the results. These two aspects are very important when applying $T L$ dosimetry to radiological emergencies.

One of the disadvantages of thermoluminescence dosimetry using manual readers, in relation to other dosimetric methods, is that the information is lost once the reading has been done. This problem can be solved by employing the previously mentioned programs, which allow us to save the information for further analysis.

The aim of this work is to show the design and assemble of a system to connect two existing TLD readers to a PC. The system includes a data acquisition card with several analogue input channels, counters, timers as well as digital inputs/outputs and software in order to achieve the acquisition and processing of data.

\section{DESCRIPTION OF THE SYSTEM}

To communicate the TLD readers with a PC, we use a data acquisition card developed in the University of Cordoba [1 3]. This card has the following characteristics:

8 analogue inputs with the following parameters: 12 bits of resolution, $500 \mathrm{KS} / \mathrm{s}, 8$ gains, programmable interval and number of conversion.

Analogue-to-digital conversion by a D/A converter with 12 bits of resolution buffered and with unipolar (0-5 V) output.

Group of $2 \times 316$ programmable bits timers.

Group of $3 \times 8$ digital Input/Output Ports.

Transference of data from the FIFO by polling. DMA and interruptions.

Complete Interface with the AT BUS.

Selection of the DMA channels and interruptions by means of jumpers.

Selection of the address range by means of a dip switch. 
This card can be divided into several blocks as shown in Fig.1. These blocks are: the interface with the AT bus, the control block, the interruption block, the timer block, the digital inputs and outputs, the analogue-to-digital conversion block, the digital-to-analogue conversion block, the analogue inputs interface and the analog outputs interface.

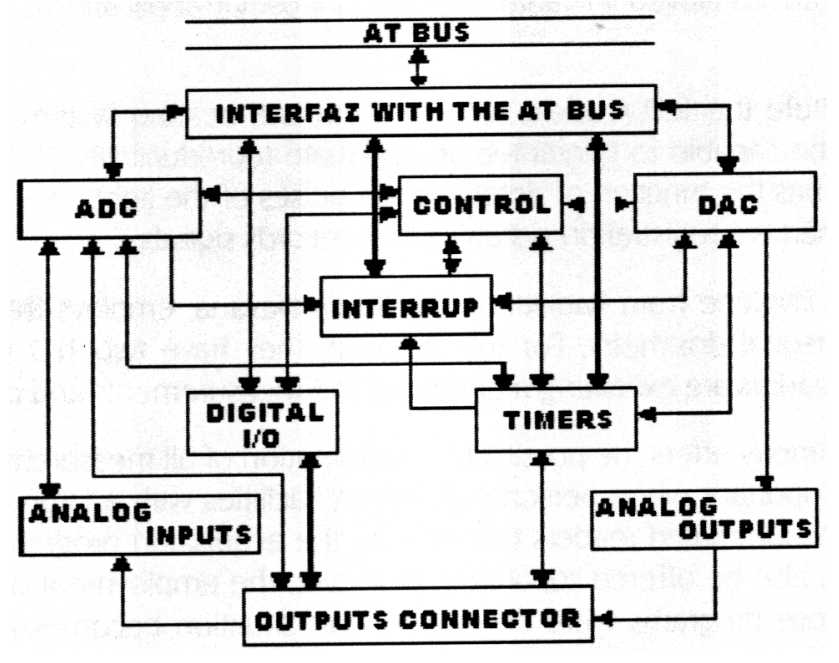

Figure 1. The $A D Q$ card block diagram

The Interface with the AT BUS Block adapts the levels of the signals to the AT BUS specifications and is constituted by drivers and jumpers.

The Control Block carries out general control functions. It generates all the signals associated to the different ways of accessing the ADQ. The block is composed by two PAL, a magnitude comparing device, two decoders and a micro switch.

The Interruptions Block: An interruption's controller $82 C 59$ constitutes this block. It provides the control of the 8 demands of interruption that exist in the card. This controller allows different possibilities like masking, activation by flank or level and rotational or fixed priority. The recognition of the interruptions by the microprocessor can be done by POLLING or by the INTA signal.

The Analogue-to-Digltal Conversion Block allows to achieve the conversion of analogue signals, which appear in one of the eight analogue input channels. We will divide it in several sub-blocks for its detailed description:

Converter and FIFO sub-block. An analogue-to-digital converter of 12 bits, $500 \mathrm{ks} / \mathrm{S}$ frequency of conversion and a range of analogue inputs of \pm 5 Volts constitute this subblock. The FIFO has a size of $512 \times 12$, extendable to $4 \mathrm{~K} \times 12$. The result of the conversions is automatically stored in the memory after de conversion is finished.

Timer sub-block The timers generate the "start of conversion" signals at the programmed frequency and count the achieved conversions.

Registers sub-block. It is constituted by four registers whose contents determine the parameters of the conversion, e.g., selected channels, triggering, gain, converter condition, reading mode, etc

Control sub-block. It controls the correct functioning of the analogue-to-digital conversion in every aspect.

The TImers block includes six timers made up of two $82 \mathrm{C54}$. They can be programmed to control the operations of the automatic analogue-to-digital and digital-to-analogue conversion. They can also be avallable for any other temporization task. 
The Digltal-to-Analogue Converslon Block. Two digital-to-analogue converters and an additional circuit that allows generating several types of output signals constitute this block:

When operating, one of the converters is controlled by the host computer microprocessor. This means that the microprocessor can transfer the corresponding data to the input latch of the converter at any time. This output can be unipolar or bipolar depending on the configuration selected by the jumper.

- The other converter operates automatically. This allows to produce an analogue signal of a specific type and duration, ieven periodical. Therefore, it provides a $4 \mathrm{~K} \times 12 \mathrm{bit}$ RAM. This memory can be written down by the microprocessor of the host computer with the appropriate value and subsequently be addressed to the latch of the converter with the programmed frequency and perlodicity.

The Analogue Input Block is a block for handling analogue input signals. The user can programme this block to get the conversion as accurate as possible. This block permits the following tasks:

Connecting with 8 channels, using only one converter.

Offering the user 8 gains for every channel so that he can choose the most suitable one to obtain the best resolution.

The Analogue Outputs Block Two operational amplifiers constitute this block. These amplifiers are in follower configuration to achieve low output Impedance and protect the converters.

The Digital Inputs/Outputs Block is constituted by the $82 \mathrm{C} 55$ and has three ports 8 bits, which are accessible in the DIN connector. The use of this circuit provides us with a great flexibility since it has several programming modes.

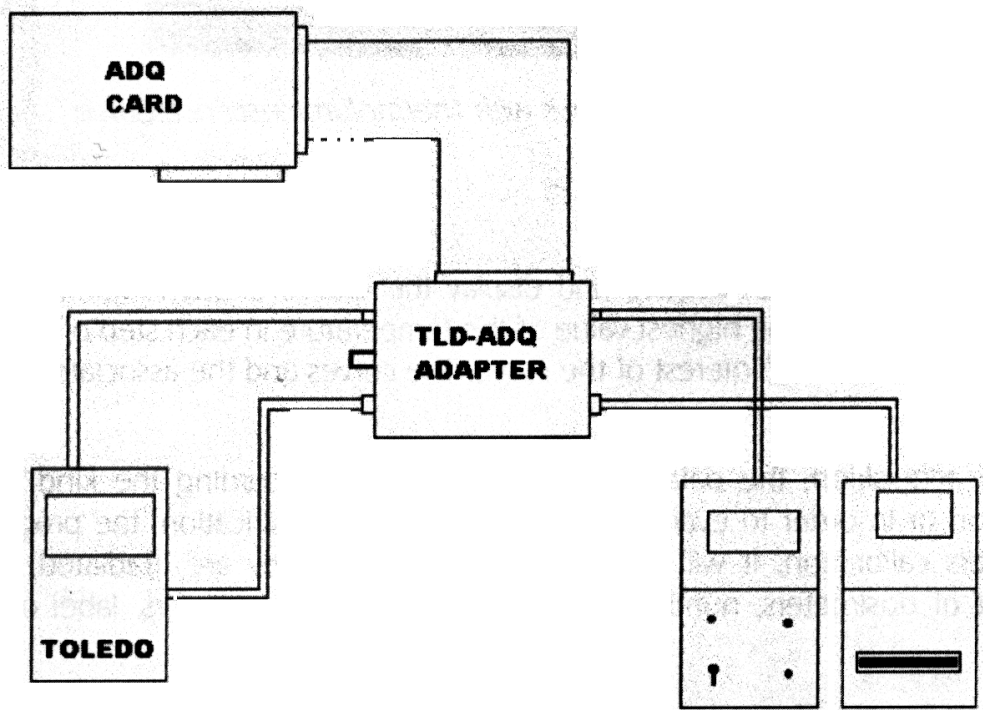

HARSHAW

Figure 2. Blocks scheme of the system

In the back panel of every TLD reader, we find the signal corresponding to the temperature at which the TL dosimeters are heated, and the pulses from the photomultiplier tube, corresponding to the light emitted by the TL dosimeters during the heating process. We connect these signals and the one that marks the beginning of the 
heating of TL dosimeters to the card by means of an adapter, as Fig.2 shows [4]. This adapter only has the function of coupling levels of signs and types of connectors.

The temperature signal is connected to the analogue input, the pulses are connected to the counter input and the signal that indicates the start of the heating process is connected to the digital input of the ADQ card. In this way the system can be programmed to build a thermoluminescence curve (Glow Curve) and to calculate the doses whenever a dosimetric pill is read.

\section{DESCRIPTION OF THE SOFTWARE}

The created system also Includes an application and control software. This software controls the card, gets the acquired data from the readers, displays the thermoluminescence curve and calculates the doses.

This program was written in Visual Basic language. There is a menu at the top of the main window (Fig 3). Some of the options are in a tool bar, below the menus. These tools speed up the access to several options in the software [4].

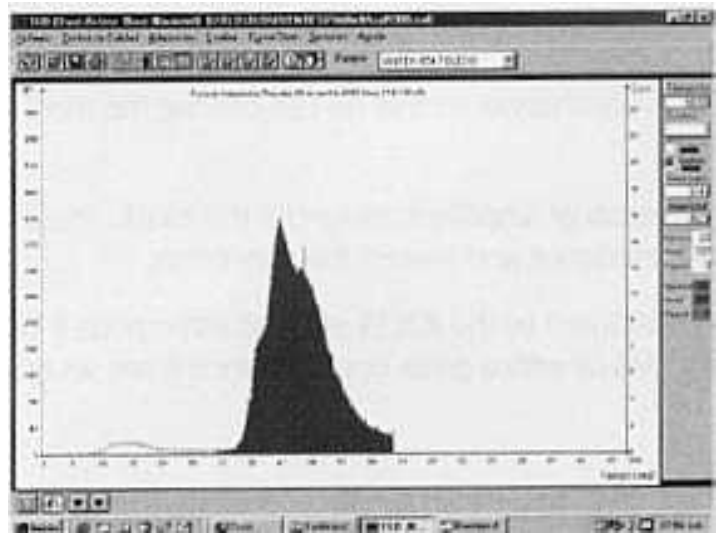

Figure3. Principal windows with Thermoluminescence Curve

Some of the most imnortant options in the menu are

Acquisition: In this option the user can acquire and display the curves of thermoluminescence associated to an examined TLD (Fig.3). It allows to get the highest value of the temperature in each step of the heating cycle as well as calculating the integral of the region of interest of the curve. The curves and the associated parameters can be saved for their future analvsis.

Before getting into the acquisition, the data files can be classified according the kind of dosimeters usage: in background, in calibration or in order to evaluate. According to this classification, the program will request specific data, e.g., for dosimeters calibration, it will ask the dose to which they are irradiated, or common data to all acquisition, like number of dosimeters, number of measurements for dosimeters, label of dosimeters group, etc. (Fig.4).

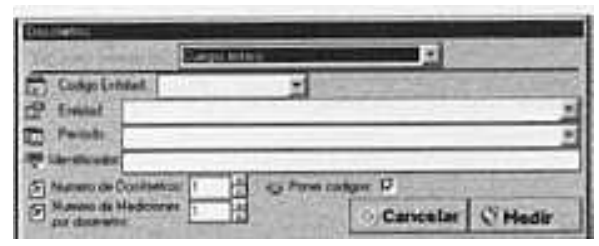

Figure 4. Demanded data for dosimeters to evaluate 
The integral of the selected area in the thermoluminescence curve, date and code of the dosimeter are saved in a database for their future processing. The program also enables the identification of the dosimeters by means of its bar code.

Quallty Control: In this option, the system achleves the operations associated with the quality parameters of the reader VINTEN 654. These include the acquisition of the signals arriving from: the internal light source (ILS) (FIg 5), the external light source (ELS), the signals produced in the dark current (DC) and the signals derived from the reading without detector. It achieves the processing and visualization of that information in time.

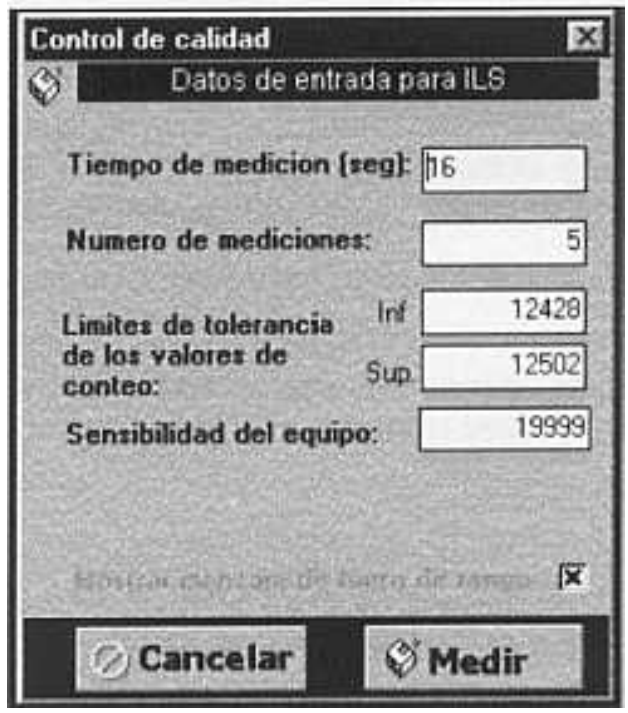

Figure 5. Input parameters for the measurement of the internal light source

Evaluation: In this option the user calculates the dose of one or several dosimeters, having the integral of the selected area of its curve. To do this, he must choose one or several calibration files, as well as one or several background files (FIg 6). The chosen files are taken from the system database, which distinguishes them by its date of acquisition or by a label that can be given to each file.

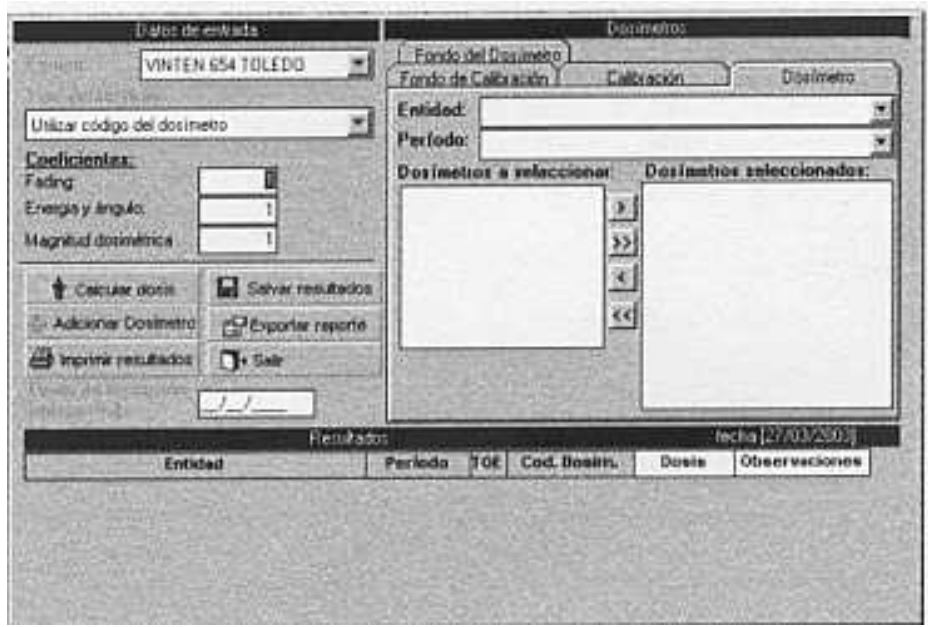

Flgure 6. Dose calculation windows 
The results of the dose calculation are organized according to the entity and the period in which the data were taken. By entity we mean the projects, the institutions, etc.

The values of dose are shown on the screen and can be printed in a definite format for their subsequent analysis. However, this is useful only when the program is used in the dose evaluation of several applications of thermoluminescence dosimetry apart from personal dosimetry. In this case the system has a database with the clients' entity, as well as the periods and codes of the dosimeters, to facilitate the use of the program. The results of the dose evaluation are sent directly to the database to be saved, and to have a control of the doses received by the occupational exposed workers clients of the personal dosimetry facility [5].

\section{CONCLUSIONS}

As a result of this work we have developed a system for the acquisition and processing of data generated by manual TLD readers. The system allows the storage of the acquired data in a computer; the processing and control of the data obtained from the test and the control of the reader. Finally, it also permits the evaluation of the dose.

The program also facilitates the transference of the evaluated doses to the database in order to administer personal dosimetry results.

The use of this system has facilitated the operation of manual TLD readers in routine control with a considerable amount of work, achieving an increase of speed in the process. Furthermore, its usage has diminished the influence of the human factor in the final result.

\section{REFERENCES}

[1] Quiles F.J., Benavides, J. I. Salcines E. G., Perez R. G. Implementación de Instrumentos Virtuales para PC. Compatibles. INFORMATICA 96, Proceedings in magnetic support (diskette ). Havana. Cuba, 1996.

[2] Rivero D, Quiles F. J., Benavides J.I. Uso de la tarjeta ADQ para automatizar experimentos. 1er NURT. 1997. Havana. Cuba, 1997.

[3] Quiles F.J., Benavides J.I., Ortiz M. A., Sáez E. y Rivero D. Mundo Electrónico. 285, pp. 62-64, 1998.

[4] Díaz E., Molina D., Rivero D., García C. Sistema para el Procesamiento de los datos de Lectores de Dosímetros Termoluminiscentes, V Regional Congress of Radiological Protection, 2001, Recife, Brazil. Proceedings in CD, 2001.

[5] Manzano de Armas et al, Sistema de gestión de datos en dosimetría personal 'Dosis'. V Regional Congress of Radiological Protection, 2001, Recife, Brazil. Proceedings in CD, 2001. 